\title{
Ipsilesional Motor Cortex Plasticity Participates in Spontaneous Hindlimb Recovery after Lateral Hemisection of the Thoracic Spinal Cord in the Rat
}

\author{
(ㄷ)Andrew R. Brown ${ }^{1,2}$ and $\oplus^{-}$Marina Martinez ${ }^{1,2,3}$ \\ ${ }^{1}$ Department of Neurosciences, Faculté de Médecine, Université de Montréal, Québec, H3T 1J4, Canada, ${ }^{2 H o ̂ p i t a l ~ d u ~ S a c r e ́-C o e u r ~ d e ~ M o n t r e ́ a l, ~ M o n t r e ́ a l, ~}$ \\ Québec, H4J 1C5, Canada, and ${ }^{3}$ Groupe de Recherche sur le Système Nerveux Central (GRSNC), Université de Montréal, Montréal, Québec, H3T 1J4, Canada
}

After an incomplete spinal cord injury (SCI) spontaneous motor recovery can occur in mammals, but the underlying neural substrates remain poorly understood. The motor cortex is crucial for skilled motor learning and the voluntary control of movement and is known to reorganize after cortical injury to promote recovery. Motor cortex plasticity has also been shown to parallel the recovery of forelimb function after cervical SCI, but whether cortical plasticity participates in hindlimb recovery after SCI remains unresolved. Using intracortical microstimulation (ICMS) mapping, behavioral and cortical inactivation techniques in the female Long-Evans rat, we evaluated the spontaneous cortical mechanisms of hindlimb motor recovery 1-5 weeks after lateral hemisection of the thoracic (T8) spinal cord that ablated the crossed corticospinal tract (CST) from the contralesional motor cortex while sparing the majority of the CST from the ipsilesional motor cortex. Hemisection initially impaired hindlimb motor function bilaterally but significant recovery occurred during the first 3 weeks. ICMS revealed time-dependent changes in motor cortex organization, characterized by a chronic abolishment of hindlimb motor representation in the contralesional motor cortex and the development of transient bilateral hindlimb representation in the ipsilesional motor cortex 3 weeks after hemisection, when significant behavioral recovery occurred. Consistently, reversible inactivation of the ipsilesional, but not the contralesional motor cortex, during skilled ladder walking 3 weeks after hemisection reinstated deficits in both hindlimbs. These findings indicate that the ipsilesional motor cortex transiently reorganizes after lateral hemisection of the thoracic spinal cord to support recovery of hindlimb motor function.

Key words: cortical inactivation; hindlimb; intracortical microstimulation; motor cortex; plasticity; spinal cord injury

Significance Statement

Partial motor recovery can occur after an incomplete spinal cord injury and is hypothesized to result from the reorganization of spared descending motor pathways. The motor cortex is crucial for the control of voluntary movement and contains topographical movement representations (motor maps) that are highly plastic. We examined the organization of hindlimb motor maps bilaterally after a lateral hemisection of the spinal cord to show that while motor maps are abolished in the deefferented cortex, the spared ipsilesional cortex transiently reorganizes to gain a representation of the affected hindlimb after injury that relates to recovery. This finding demonstrates that plasticity in the ipsilesional motor cortex at early time points after spinal cord hemisection is initially important to support motor recovery.

\section{Introduction}

The motor cortex is crucial for skilled motor learning and voluntary control of movement. Motor repertoire is somatotopically

\footnotetext{
Received April 21, 2018; revised Aug. 20, 2018; accepted Sept. 29, 2018.

Author contributions: M.M. designed research; A.R.B. performed research; A.R.B. and M.M. analyzed data; A.R.B. and M.M. wrote the paper.

This work was supported by the Canadian Institutes for Health Research (CIHR; MOP-142288) to M.M., a salary award from Fonds de Recherche Québec Santé (FRQS) to M.M., and fellowships from the Hotchkiss Brain Institute (12/01/2014-3/31/2016) and FRQS (5/01/2016-4/31/2020) to A.R.B. Wethank Dr. G.C. Teskey at the Hotchkiss Brain Institute for the generous loaning of equipment for cortical inactivation and $Y$. Bensaada for assistance with histology, and Drs. N. Dancause, T. Drew, and S. Rossignol for their helpful comments during manuscript revision.
}

mapped onto the cortex, and cortical movement representations (motor maps) are highly plastic in humans (Cohen et al., 1991; Classen et al., 1998; Karni et al., 1998), primates (Nudo et al., 1996), and rats (Kleim et al., 2004), exhibiting reorganization tuned by experience. Following damage to the motor cortex, mo-

\footnotetext{
The authors declare no competing financial interests.
}

Correspondence should be addressed to Dr. Marina Martinez, Département de Neurosciences, Université de Montréal, 2960 Chemin de la Tour, Pavillon PG. Desmarais, Local 2124, Montréal, QC H3T 1J4, Canada. E-mail: marina.martinez@umontreal.ca.

https://doi.org/10.1523/JNEUROSCI.1062-18.2018

Copyright $\odot 2018$ the authors $\quad 0270-6474 / 18 / 389977-12 \$ 15.00 / 0$ 
tor maps can reorganize to regain representation of affected body parts that were lost initially after the injury (Wittenberg, 2010). Motor map reorganization is observed after damage to the motor cortex in both stroke (Nudo and Milliken, 1996; Traversa et al., 1997; Biernaskie and Corbett, 2001; Touvykine et al., 2016) and traumatic brain injury (Nishibe et al., 2010; Combs et al., 2016), as well as after spinal cord injury (SCI; Girgis et al., 2007; Martinez et al., 2010; Oza and Giszter, 2014; Hilton et al., 2016).

After unilateral cervical SCI in the rat that disrupts corticospinal tract (CST) fibers from the opposite motor cortex (contralesional), the forelimb on the side of the lesion (ipsilesional) partially recovers spontaneously during the first month, despite persistent deficits in distal movements (Martinez et al., 2010). Although the overall forelimb motor map size in the deefferented contralesional motor cortex is drastically reduced after injury, the representation of proximal movements is significantly increased and is consistent with recovery (Martinez et al., 2010). Skilled training of the ipsilesional forelimb after SCI has further been shown to facilitate recovery of distal movements and is paralleled by an expansion of wrist representation in the contralesional motor cortex (Girgis et al., 2007). Although the cortical mechanisms of forelimb recovery after SCI have received attention, there are only a few reports on the reorganization of hindlimb motor cortex and hindlimb motor recovery after SCI. Among these studies, almost all have focused on examining spontaneous reorganization of the de-efferented motor cortex and consistently show an abolishment of hindlimb motor maps for up to 4 weeks after injury (Fouad et al., 2001; Frost et al., 2015; Manohar et al., 2017). Hindlimb motor maps are re-established in the de-efferented cortex 12 weeks after unilateral SCI due to intraspinal axonal remodeling, however, this occurs long after the time in which maximal recovery is observed (Bareyre et al., 2004). After unilateral motor cortex injury, reorganization of motor maps in the uninjured hemisphere is observed and may contribute to functional recovery (Axelson et al., 2013). The question of whether similar plasticity in hindlimb motor cortex with residual CST connectivity to the spinal cord at early time points after unilateral SCI participates in hindlimb motor recovery is not known.

In this study, we combined behavioral, electrophysiological and in vivo cortical inactivation techniques to evaluate whether hindlimb motor cortex spontaneously, in the absence of any specific rehabilitation training, reorganizes after unilateral SCI and whether cortical plasticity relates to functional motor recovery. Following lateral hemisection of the thoracic (T8) spinal cord in rats, in which the main dorsomedial and the minor dorsolateral CST fibers from the ipsilesional and contralesional motor cortex are respectively spared and disrupted, we evaluated locomotor performance and hindlimb motor map organization bilaterally in the intact state and for 5 weeks after injury using intracortical microstimulation (ICMS). Hemisection initially impaired hindlimb motor function bilaterally but significant partial recovery occurred by the third week. Recovery was paralleled by dynamic bilateral cortical changes, characterized by a transient re-establishment of representation of the affected hindlimb in the ipsilesional motor cortex and a chronic abolishment of hindlimb motor maps in the contralesional motor cortex. Consistently, cortical inactivation of the ipsilesional, but not contralesional, motor cortex induced bilateral hindlimb deficits 3 weeks after hemisection, but not in the intact state. Results suggest a role for transient ipsilesional motor cortex plasticity in supporting spontaneous partial hindlimb motor recovery after unilateral SCI in the rat. This work has been presented in abstract form (Brown and Martinez, 2016).

\section{Materials and Methods}

Animals

One hundred and twenty-seven young-adult female Long-Evans rats between 12 and 16 weeks of age (221-307 g) at the time of electrophysiological mapping were used in this study. All rats were obtained from Charles River Laboratories (rat line 006) and housed individually in clear polycarbonate cages in a colony room maintained on a $12 \mathrm{~h}$ light/dark cycle at $21^{\circ} \mathrm{C}$. Rats were provided ad libitum access to food and water (Prolab RMH 2500 lab diet, PMI Nutrition International) throughout the duration of their housing. For ICMS experiments, 69 rats were excluded from analyses due do either incomplete damage to the ipsilesional dorsal CST or overextended damage to the contralesional CST and right cord $(n=65)$, or inconsistent anesthetic plane and evoked movements during ICMS $(n=4)$. For cortical inactivation experiments, four rats were excluded from analyses because of overextended damage to the contralesional CST $(n=3)$ or headcap loss $(n=1)$. Of the 54 rats included in the results, experimentation for 22 was conducted at Université de Montréal, and for 32 at the University of Calgary. No differences were observed between experiments performed at the two different locations with respect to lesion size, behavioral measures, or motor map organization ( $t$ tests, all $p>0.05$ ). All procedures followed the guidelines of the Canadian Council on Animal Care and were approved by the Health Sciences Animal Care Committee of the University of Calgary (protocol \#AC14-0145) and the ethics committee at the Université de Montréal ( protocol \#15-125).

\section{Experimental approach}

Global locomotor and postural abilities were first examined during locomotion in the open field. On the same day, ICMS was used to assess the organization of hindlimb motor maps within both cortices either in the intact state or at the end of a recovery period ranging $1-5$ weeks following a lateral hemisection of the thoracic (T8) spinal cord in a between-groups time course design in separate groups of rats (6 groups, $n=8$ per group; Fig. $1 A, B)$. Next, we investigated the contribution of the ipsilesional and contralesional motor cortex to hindlimb recovery using reversible cortical inactivation during ladder walking before and following hemisection in a within-subjects design in three rats with five trials conducted under each inactivation condition and time point (Fig. 1C). Cortical inactivation was achieved using chronically implanted cryoloops targeting the hindlimb motor cortex bilaterally. Following a week of recovery, baseline horizontal ladder walking performance was assessed before and during inactivation of either the ipsilesional or contralesional cortex. Implanted rats were then subjected to a lateral hemisection of the thoracic (T8) spinal cord and underwent weekly behavioral assessment on the horizontal ladder before and during inactivation of either the ipsilesional or contralesional motor cortex for 5 weeks.

\section{Spinal cord injury}

Anesthesia was induced with a mixture of isoflurane (3\% induction, $0.5-3 \%$ maintenance) and oxygen. Once anesthetized, the trunk was shaved, disinfected with iodine, and the rat placed in a stereotaxic frame. Core body temperature was monitored continuously by rectal thermometer and maintained at $37^{\circ} \mathrm{C}$ using a feedback-controlled heating pad. Under aseptic conditions, a $2 \mathrm{~cm}$ midline incision in the skin was made overlaying the T6-T10 vertebrae, identified by palpitation from the protuberance of the second thoracic vertebra (Vichaya et al., 2009). The skin and superficial muscles were retracted and the paravertebral muscles inserting on the dorsal aspect of the T7-T9 vertebra were dissected. A bilateral laminectomy of the T8 vertebra exposed the dorsal surface of the spinal cord, the dura was incised, and droplets of lidocaine (2\%) were applied to the spinal cord to decrease spinal reflexes. A lateral hemisection of the left side of the spinal cord was performed under microscope visualization with a dissecting knife and completed with iridectomy scissors. Gelfoam (Pfizer) was placed over the exposed cord as well in the cavity formed from the muscle dissection. Finally, the muscle layers and skin were sutured. Buprenorphine hydrochloride $(0.05 \mathrm{mg} / \mathrm{kg}$, s.c. $)$ was 
A

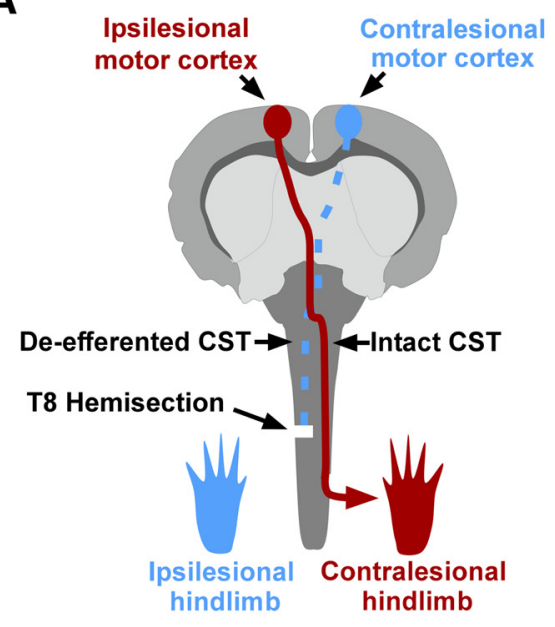

B
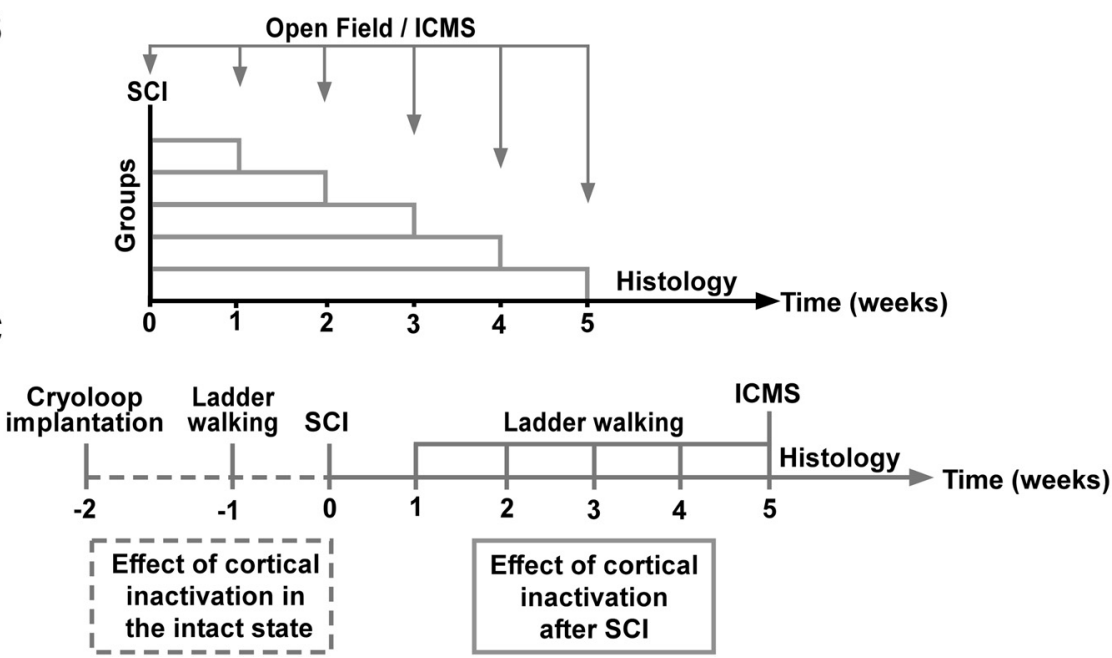

Figure 1. Spinal cord injury model and experimental design. $A$, Schematic representation of the SCI model. Lateral hemisection of the thoracic (T8) spinal cord severs the crossed CST originating from the contralesional hindlimb motor cortex, which no longer has access to the motoneurons that innervate the ipsilesional hindlimb. In contrast, crossed CST projections from the ipsilesional motor cortex are spared by the hemisection and still have an access to the spinal motor circuits. $\boldsymbol{B}$, Hindlimb motor performance was assessed using a neurological rating scale in an open field and bilateral cortical hindlimb motor maps were derived using ICMS in separate groups of rats before and $1-5$ weeks after hemisection ( $n=8$ rats/group). $\boldsymbol{C}$, Cryoloops targeting ipsilesional and contralesional hindlimb motor cortices were chronically implanted in three rats. Ladder walking was assessed before and during separate inactivation of the ipsilesional or contralesional hindlimb motor cortex before and for 5 weeks after hemisection in the same rats.

provided prophylactically for pain 20 min before the end of the surgery and for $3 \mathrm{~d}$ after. Rats also received Baytril (10 mg/kg, s.c.; Bayer Animal Health) antibiotic and $5 \mathrm{ml}$ of lactated ringer's solution (i.p.) for fluid resuscitation. Rats were monitored throughout the postoperative period to ensure proper micturition. Manual expression of the bladder was not required.

\section{Cryoloop implantation for cortical inactivation}

Cryoloop construction has been described previously (Brown and Teskey, 2014). Loops fashioned from 23 gauge $(0.635 \mathrm{~mm}$ outer diameter $\times$ $0.33 \mathrm{~mm}$ inner diameter) hypodermic stainless steel tubing. A linear 2 $\mathrm{mm}$ portion of the loop was shaped to conform to the surface to the cortical surface. A microthermocouple made from 30 AWG gauge Teflon insulated copper and constantan wire was soldered to the union of the inlet and outlet tubes, which were led through a plastic, outsidethreaded, cylinder pedestal (1.7 $\mathrm{mm}$ height, $3.5 \mathrm{~mm}$ diameter). The microthermocouple wire was attached to terminating connector pins (Omega Engineering) and dental acrylic was used encase the cryoloop tubes, pedestal, and microthermocouple assembly. A detailed description of cryoloop manufacturing and operation is provided by Lomber et al. (1999). Rats were placed under general, surgical plane anesthesia with isoflurane (3\% induction, $0.5-3 \%$ maintenance) and oxygen and fixed in a stereotaxic instrument (Kopf) with the incisor bar set to skull flat. The local anesthetic lidocaine (2\%) was administered subcutaneously at the incision site in the scalp. The skull was exposed, a partial craniotomy of frontal bones was made over the sensorimotor cortex, and dura reflected. Five stainless steel jeweler screws were placed in the skull adjacent to the craniotomy to permit firm anchoring of the cryoloop headcap assembly. The cryoloop assembly was disinfected with $70 \%$ ethanol and positioned in place over the exposed cortex, resting on the pial surface. Loops targeting the hindlimb motor cortex were implanted bilaterally $-1.5 \mathrm{~mm}$ posterior to bregma and $1.5-3.5 \mathrm{~mm}$ lateral to midline. Dura was replaced and a silicone elastomer (Kwik-Sil, World Precision Instruments) was used to fill the cranial vault. Dental acrylic was used to secure the cryoloop assembly to the skull and screws. The scalp was sutured around the cryoloop and acrylic headcap. Buprenorphine hydrochloride (0.05 $\mathrm{mg} / \mathrm{kg}$, s.c.) was provided prophylactically for pain $20 \mathrm{~min}$ before the end of the surgery and for $3 \mathrm{~d}$ after. Rats also received Baytril (10 mg/kg, s.c.; Bayer Animal Health) antibiotic.

The surgical procedure to implant cryoloops, their presence in contact with the cortex, and their operation has been shown not to disrupt the structural or functional integrity of the cerebrum (Lomber and Payne,
1996; Yang et al., 2006; Brown and Teskey, 2014). Cryoloop dimensions, holding temperature, and implantation coordinates were chosen to provide effective inactivation of the hindlimb cortical representation based on cortical temperature recordings revealing an inactivation area of 7 $\mathrm{mm}^{2}$ where tissue temperatures at depth $(1.5 \mathrm{~mm})$ were held $<20^{\circ} \mathrm{C}$ (Lomber et al., 1999) in addition to the abolition of evoked ICMS responses (Brown and Teskey, 2014). In validation experiments, acute inactivation of the hindlimb motor cortex was shown to reversibly abolish ICMS-evoked hindlimb, but not forelimb movement in the anesthetized rat indicating selective targeting of the hindlimb cortex. Following behavioral assessment, implanted rats underwent electrophysiological mapping to validate correct loop placement over hindlimb motor cortex and verify cortical integrity after implantation by assessing evoked responses to ICMS stimulation. We observed hindlimb-responsive sites to ICMS within the ipsilesional cortex underlying cryoloop coordinates in all cases.

\section{Inactivation of hindlimb motor cortex}

The cortex was cooled by pumping chilled methanol from a methanol/ dry ice bath mixture through Teflon tubing connected to cryoloop inlet/ outlet tubes with a reciprocating piston pumps (QG150-Q1-CSC, Fluid Metering) to maintain a constant loop temperature of $4^{\circ} \mathrm{C}$. Loop temperatures were monitored (HH-25TC digital thermometer, Omega Engineering) and controlled to $\pm 1^{\circ} \mathrm{C}$ of the desired value by controlling the rate of methanol flow. Cortical inactivation was terminated by stopping methanol flow and allowing passive re-warming of the cortex. The order of behavioral testing between inactivation conditions (ipsilesional, contralesional) was counterbalanced between sessions. Five minutes were given in between testing sessions to allow cortical temperatures to return to normal values.

\section{Behavioral assessment}

Open-field score. To evaluate spontaneous recovery of global locomotor and postural abilities, rats were assessed in an open field and scored using an adapted version of a neurological scoring scale originally developed for evaluating locomotor function after cervical SCI (Martinez et al., 2009). Rats were tested individually for $4 \mathrm{~min}$ in a circular Plexiglas open field (96 cm diameter, $40 \mathrm{~cm}$ wall height) under low light to encourage exploratory behavior. Testing sessions were recorded for off-line analyses (30 frames/s). Behavioral deficits were categorized for both hindlimbs separately by evaluating specific parameters of articular movement amplitude, weight support, fine distal positioning, stepping abilities, and forelimb- 
A

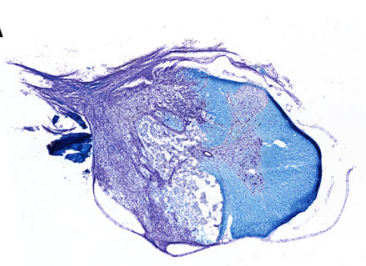

C

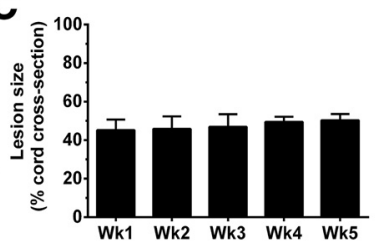

B

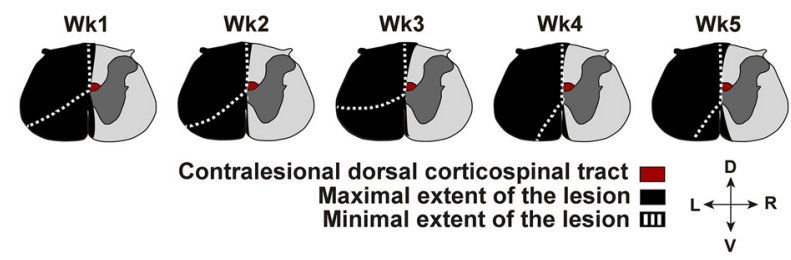

Figure 2. Extent of the spinal lesions. $A$, Microphotograph of a coronal spinal cord section at thoracic (T8) level after lateral hemisection stained with cresyl violet (cell bodies, purple) and luxol fast blue (myelin, blue) indicating damage to gray and white matter in the left hemicord including the dorsal CST (shown in $\boldsymbol{B}$ ) with majority sparing of the right dorsal corticospinal tract. Scale bar, $500 \mu \mathrm{m}$. B, Schematic drawings of the largest (black fill) and smallest (white dashed lines) lesion area within each group. D, Dorsal; $V$, ventral; $L$, left; $R$, right. $C$, Comparisons of the extent of maximum cross section lesion area as a percentage of total cross section area in hemisection groups ( $n=8 \mathrm{rats} / \mathrm{group}$ ). No statistical differences in lesion size was observed between groups (ANOVA, $p=0.219$ ). Data are plotted as group mean \pm SD. See also Figure 2-1 (available at https://doi.org/10.1523/JNEUROSCI.1062-18.2018.f2-1) for individual values and Figure 3 demonstrating that contralesional hindlimb motor maps are abolished, whereas the majority of ipsilesional hindlimb motor map area is preserved acutely $(1 \mathrm{~h})$ after hemisection.

hindlimb coordination. Scores were tallied by evaluating: (1) articular movement amplitude of hip, knee, and ankle $(0=$ absent, $1=$ slight, $2=$ normal); (2) stationary and active weight support of the limb $(0=a b-$ sent, 1 = present $) ;(3)$ digit position of hindlimb $(0=$ flexed, $1=$ atonic, $2=$ extended); (4) paw placement at initial contact $(0=$ dorsal, $1=$ internal/external rotation, 2 = parallel); (5) paw orientation during lift ( 1 = internal/external rotation, 2 = parallel); (6) movement during swing ( $1=$ irregular, $2=$ regular); (7) coordination between the forelimb and $\operatorname{hindlimb}(0=$ absent, $1=$ occasional, $2=$ frequent, $3=$ consistent $)$; and (8) tail position $(0=$ down, $1=$ up $)$ for a maximum of 20 points. A sample scoring rubric is provided in Extended Data Figure 4-1, available at https://doi.org/10.1523/JNEUROSCI.1062-18.2018.f4-1.

Horizontal ladder-rung walking. To evaluate skilled voluntary control of the limbs, motor performance was assessed before and during independent inactivation of the ipsilesional and contralesional hindlimb motor cortex using the horizontal ladder-rung walking test (Soblosky et al., 1997). Rats were trained to walk across a ladder ( $130 \mathrm{~cm}$ long; rungs of 3 $\mathrm{mm}$ diameter regularly spaced by $2 \mathrm{~cm}$ ). A mirror was positioned $45^{\circ}$ under the ladder to facilitate video recording of paw placement and movement from both lateral and ventral views. The percentage of footfaults made over the number of total consecutive steps for each limb was used to characterize locomotor performance (Metz and Whishaw, 2002). Foot-faults were defined as either (1) a total miss, where a deep fall of the limb occurs after the rat misses the rung and fails to touch it; (2) a deep slip, where a deep fall of the limb occurs after the rat slips off the rung causing a loss of balance and body posture; or (3) a slight slip, where the limb slips off the rung but does not cause a loss of balance or body posture and the animal continues to walk. The percentage of forelimb and hindlimb foot-faults for each rat was calculated as the number of footfaults made by each limb referenced to the number of steps made by each limb. Five trials were conducted per rat under each testing condition and time point and the total percentage of foot-faults was used for analyses. Testing sessions were recorded for later off-line analyses (30 frames/s).

Electrophysiological mapping of hindlimb motor cortex

Standard ICMS techniques (Neafsey et al., 1986; Brown et al., 2009; Martinez et al., 2010), detailed in this section, were used to generate motor maps of the hindlimb motor cortex. Rats were anesthetized with ketamine hydrochloride ( $80 \mathrm{mg} / \mathrm{kg}$, i.p.) and xylazine $(5 \mathrm{mg} / \mathrm{kg}$, i.p.) and
A
Ipsilesional cortex

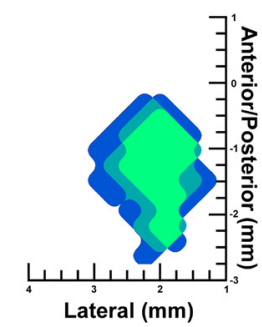

Contralesional cortex
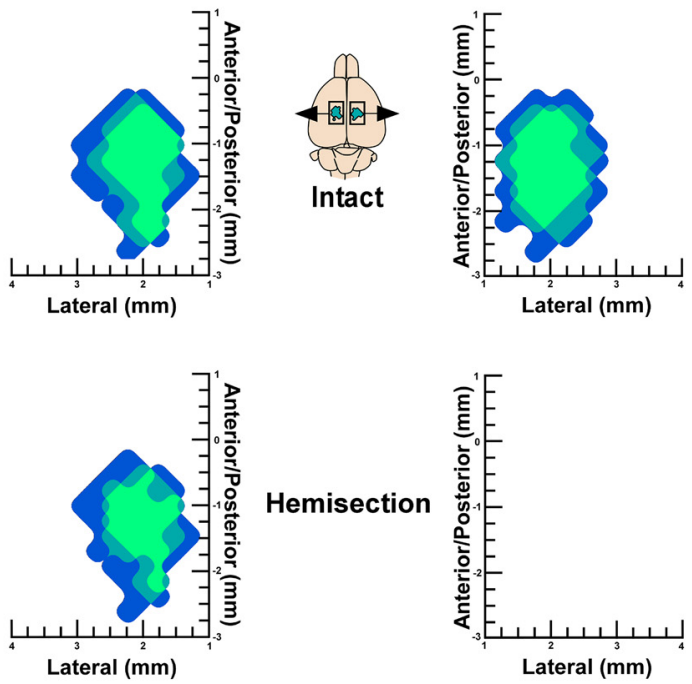

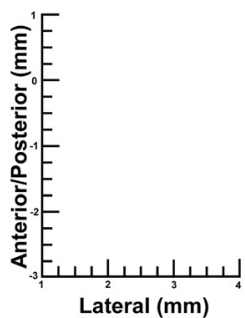

Lateral $(\mathbf{m m})$
B

Hindlimb map overlap between rats

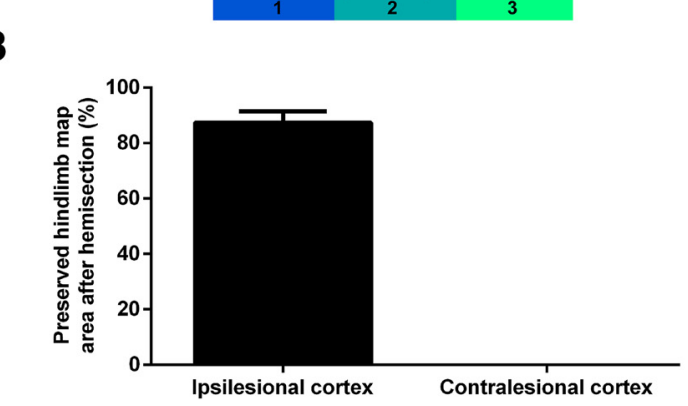

Figure 3. Ipsilesional hindlimb motor maps are preserved $1 \mathrm{~h}$ after hemisection. A, Surface plots showing the frequency distribution of hindlimb motor maps derived with ICMS in the intact state and $1 \mathrm{~h}$ after hemisection ( $n=3$ rats). After hemisection, hindlimb motor maps were abolished in the contralesional cortex and preserved in the ipsilesional cortex. B, Quantification of hindlimb motor map area after hemisection relative to the intact state (\%). Data are plotted as group mean \pm SD.

secured in a stereotaxic frame with the incisor bar set to skull flat. Supplemental alternating injections of either ketamine $(25 \mathrm{mg} / \mathrm{kg})$ or a mixture of ketamine $(17 \mathrm{mg} / \mathrm{kg})$ and xylazine $(2 \mathrm{mg} / \mathrm{kg})$ were given i.p. as required throughout surgery to maintain a constant level of anesthesia as determined by monitoring vibrissae whisking, breathing rate, and foot and tail reflex in response to a gentle pinch. A $7 \times 5 \mathrm{~mm}$ craniotomy was performed over both sensorimotor cortices. The window approximately extended between $3 \mathrm{~mm}$ anterior to and $4 \mathrm{~mm}$ posterior to bregma and from midline to $5 \mathrm{~mm}$ lateral. A small puncture was made in the cisterna magna with an 18 gauge hypodermic needle to reduce cortical edema. Dura was removed and silicone fluid (Factor II) heated to body temperature was used to cover the cranial window. A $32 \times$ image of the exposed portion of the brain was captured using digital camera (Canon Canada) coupled to a Stemi 2000-C stereomicroscope (Carl Zeiss), and displayed on a personal computer. A grid of $500 \mu \mathrm{m}$ squares was then overlaid on the digital image using Canvas imaging software (v11, ACD Systems). Penetrations were performed at the intersections of the grid lines and in the center of each square to give an interpenetration distance of $354 \mu \mathrm{m}$, except when located over a blood vessel in which case a penetration was not performed.

Glass-coated platinum/iridium microelectrodes with an input impedance of $0.5 \pm 0.1 \mathrm{M} \Omega(1000 \mathrm{~Hz}, 10 \mathrm{nA})$ were used (FHC). Electrode impedance was monitored throughout mapping experimentation and electrodes were discarded when impedance measurements dropped $<0.3 \mathrm{M} \Omega$. Electrodes were guided into the neocortex to a depth of 1550 $\mu \mathrm{m}$ via microdrive (David Kopf Instruments model 2650), correspond- 
A

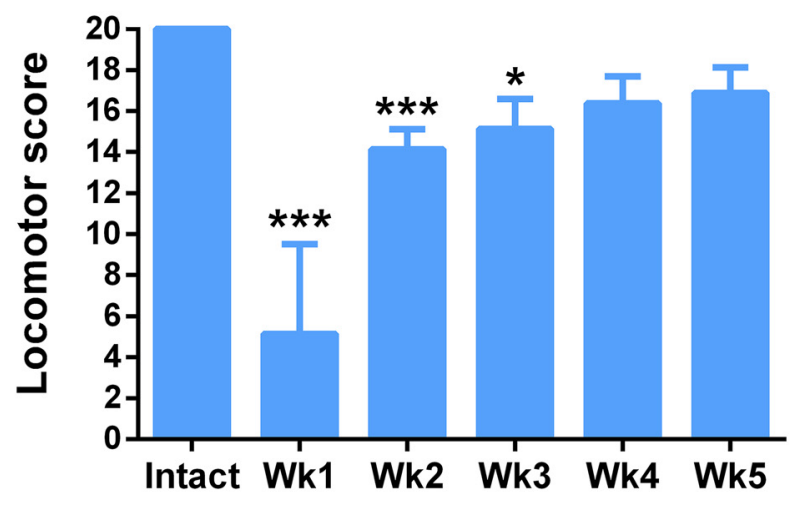

B

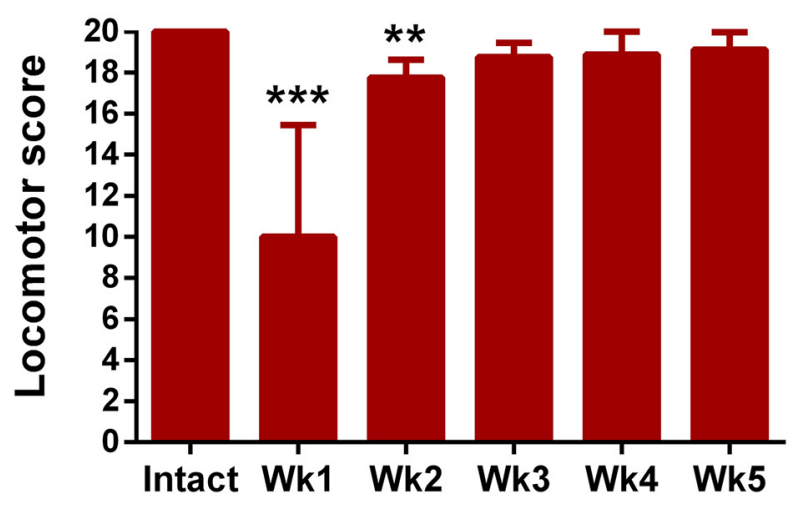

Figure 4. Postoperative time course of changes in locomotor performance in the open field. $\boldsymbol{A}$, Ipsilesional and $\boldsymbol{B}$, contralesional hindlimb performance was significantly impaired from intact values during the first 3 and 2 weeks after hemisection. Data are plotted as group mean $\pm S D$ ( $n=8$ rats/group). Statistical evaluation was performed with Kruskal-Wallis and Dunn's multiple-comparison tests, asterisks indicate significances: ${ }^{*} p<0.05$, ${ }^{* *} p<0.01$, ${ }^{* * *} p<0.001$. See also Figure 2-1 (available at https://doi.org/10.1523/JNEUROSCl.106218.2018.f2-1) for individual values and Figure 4-1 (available at https://doi.org/10.1523/ JNEUROSCI.1062-18.2018.f4-1) for the scoring rubric.

ing to the somatic region of neocortical layer $\mathrm{V}$ pyramidal neurons (Teskey et al., 2002). Movements can be readily elicited within a large (1550 \pm $150 \mu \mathrm{m}$ depth from surface) profile of the motor cortex with negligible effect on their nature or threshold (Young et al., 2011). An isolated pulse stimulator (Model 2100, A-M Systems) was used to deliver electrical current. A ground stimulation lead was placed in contact with exposed neck musculature from the incision to puncture the cisterna magna. Stimulation trains were $40 \mathrm{~ms}$ long and consisted of 13 biphasic cathodallead pulses, each $200 \mu \mathrm{s}$ in duration, delivered at a frequency of $333 \mathrm{~Hz}$ with a train rate of $1 \mathrm{~Hz}$.

The hip was affixed to a spinal unit allowing free range of motion of the hindlimbs, with the abdomen supported by an elevated homeostatic heating pad. To determine a movement threshold, current intensity was increased from $0 \mu \mathrm{A}$, until a movement was elicited or to maximum of $100 \mu \mathrm{A}$, and then decreased until the movement was no longer present. Any penetration site that failed to elicit a movement at this maximum intensity was considered nonresponsive. A maximum of 10 trains of pulses were delivered to any given penetration site. The border of the hindlimb motor map was first defined consisting of either non-hindlimb movements (neck, jaw, vibrissae, trunk, tail, and forelimb) or nonresponsive points in a systematic fashion. Once the border was defined, the central hindlimb map was filled in. Hindlimb movements were classified as either flexion or extension of the hip, knee, ankle, or toes. This proce- dure was used to minimize the likelihood of the microstimulation session affecting the map boundaries (Nudo et al., 1990). Throughout the surgery, anesthetic levels were monitored every $15 \mathrm{~min}$ by verifying the thresholds for previously defined positive-response sites. Movements were monitored visually during electrophysiological mapping and videorecorded for subsequent analysis (30 frames/s). A light-emitting diode synchronized with stimulator output was fixed to the stereotaxic frame in the camera field-of-view. Each responsive site was taken to represent $0.125 \mathrm{~mm}^{2}$ of cortical surface $(354 \times 354 \mu \mathrm{m})$. Mean stimulation thresholds for hindlimb movements were also calculated. A change in map organization was considered as alterations in the total hindlimb representation size as well as the size of representation of each hindlimb joint, and the lateralization of the evoked movement (ipsilateral, contralateral, or bilateral limb movement) between groups. Threshold analyses were also performed to assess group differences in the minimum current intensity required to elicit hindlimb movements during ICMS.

\section{Histological controls}

Following ICMS, rats were given a lethal dose of sodium pentobarbital and transcardially perfused with $150 \mathrm{ml}$ of $0.1 \mathrm{M}$ PBS followed with 250 $\mathrm{ml}$ of cold paraformaldehyde (PFA; $4 \%$ ) in PBS. The spinal cord between T6 and T10 vertebral segments was carefully dissected out and postfixed for $12 \mathrm{~h}$ in PFA. Tissue was then cryoprotected in $30 \%$ sucrose for $48 \mathrm{~h}$ or until sunk. A Cryostat was used to cut $40 \mu \mathrm{m}$ frozen coronal sections. Every third section was mounted onto gelatin-coated slides and stained with cresyl violet $(0.5 \%)$ to visualize cell bodies in the spinal gray matter and luxol fast blue $(0.1 \%)$ to visualize myelin in the spinal white matter. Hemisection lesion extent was quantified by evaluation of the maximal percentage of damaged tissue of the cord observed in the coronal plane as described previously (Martinez et al., 2010).

\section{Experimental design and statistical}

analyses

The experimental design for the different experiments is described in previous subsections. All rats were randomly assigned to experimental groups. All experiments were conducted by A.R.B. and behavioral experiments were blindly analyzed by M.M. to avoid experimental bias. To compare the hemisection lesion size between postoperative groups, oneway ANOVA was used. Ordinal open-field locomotor scores were assessed with the Kruskal-Wallis nonparametric tests supplemented with Dunn's multiple-comparison tests (Benjamini-Hochberg FDR correction) to examine differences between intact and postoperative time points. As hindlimb responses were not elicited 1 week after hemisection, ANOVA supplemented with Tukey HSD multiple-comparison tests were used to compare electrophysiological mapping data (motor map size and movement thresholds) between intact and postoperative time points $2-5$ weeks after hemisection ( 5 groups, $n=8$ rats/group). ANOVA supplemented with Tukey HSD multiple-comparison tests were also used to examine the differences between all intact and postoperative hemisection time points for the amounts of ketamine and xylazine anesthetic delivered during ICMS (6 groups, $n=8$ rats/group). The percentage of cortical stimulation sites evoking bilateral movement at 3 weeks after hemisection compared with the intact state were not normally distributed due to an absence of bilateral movements being evoked in the intact state, and were assessed using a nonparametric Mann-Whitney test ( 2 groups, $n=8$ rats/group). A two-factor repeated-measures ANOVA supplemented with Bonferroni-corrected multiple-comparison tests, using intact and postlesion time points as one factor and inactivation condition as a second factor, was used to assess horizontal ladder crossing performance for cortical inactivation behavioral data. Post hoc comparison testing was only performed when a main effect was observed. Statistical analyses were performed using R 3.4.3 (R Core Team, https://www.R-project.org/) and GraphPad Prism 6. All analyses were two-tailed. An experiment-wide $\alpha$ level of 0.05 was used. Data are presented as group mean $\pm \mathrm{SD} .{ }^{\star} p<0.05,{ }^{* *} p<0.01,{ }^{* * *} p<0.001$.

\section{Results}

Extent of spinal cord lesions

In all rats, hemisections targeted the left side of the spinal cord, and although somewhat variable between rats, the lesions were mainly 

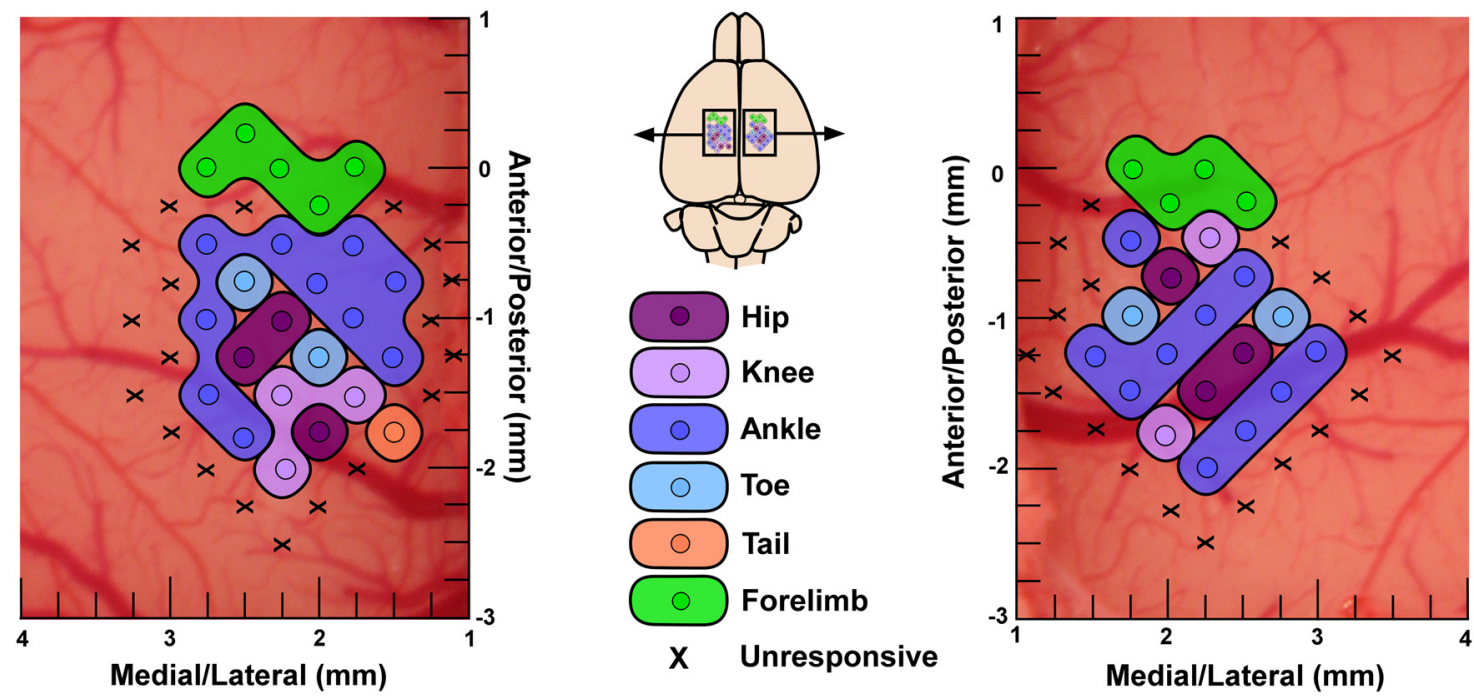

Figure 5. Representative hindlimb motor maps in an intact rat derived with ICMS. Stimulation sites evoking contralateral hindlimb movements of the hip (purple), knee (pink), ankle (dark blue), and toe (light blue) at $\leq 100 \mu \mathrm{A}$. The hindlimb representation is bounded by forelimb responses at its anterior border (green). Tail movement is indicated in orange. Unresponsive stimulation sites (showed by $\mathrm{X}$ ) mark the medial, lateral, and posterior hindlimb representation borders.

confined to the left side of the cord. The hemisections disrupted the crossed CST from the contralesional motor cortex while sparing the majority of the crossed CST from the ipsilesional motor cortex (Fig. $2 A, B)$. No significant difference in hemisection lesion size, calculated as the maximal percentage of damaged cross-sectional cord area, was found between postlesion groups $\left(F_{(4,35)}=1.515, p=\right.$ 0.219, ANOVA; Fig. $2 C$ and Fig. 2-1 available at https://doi.org/ 10.1523/JNEUROSCI.1062-18.2018.f2-1). To ensure that the lesion technique spared the majority of the CST on one side only ICMS was performed in an additional three rats to probe hindlimb motor maps in the intact state and $1 \mathrm{~h}$ after injury. Hemisection abolished hindlimb movements evoked in the contralesional hemisphere and preserved $87.1 \pm 4.1 \%$ of hindlimb responses in the ipsilesional hemisphere (Fig. 3).

\section{SCI results in spontaneous open-field locomotor recovery}

For the first 2-3 d following hemisection, the primary consequence of the injury was a flaccid paresis of the ipsilesional hindlimb. Performance of the ipsilesional hindlimb was significantly impacted by the lesion $\left(H_{(6,47)}=36.8, p=2.65 \mathrm{E}-07\right.$, KruskalWallis; Fig. $4 A$ and Fig. 2-1 available at https://doi.org/10.1523/ JNEUROSCI.1062-18.2018.f2-1) over the first 3 weeks (Week 1: $p=$ 6.48E-07, Week 2: $p=3.20 \mathrm{E}-03$, Week 3: $p=0.0105$, Dunn's tests). A residual deficit in the ipsilesional hindlimb was notable external rotation of the paw during lift. A persistent disruption of forelimb-hindlimb coupling was also observed on the side of the lesion. The contralesional hindlimb exhibited significant $\left(H_{(6,47)}=32.1\right.$, $p=5.68 \mathrm{E}-06$, Kruskal-Wallis; Fig. $4 B)$, but smaller, alterations in hindlimb performance by comparison to the ipsilesional hindlimb during the first 2 weeks (Week 1: $p=6.0 \mathrm{E}-06$, Week 2: $p=0.0043$, Dunn's tests) that could reflect compensation for the opposite limb or deficits resulting from a lack of postural stability, weight support, and consistent stepping. The hemisection did not impact forelimb function in any rat.

\section{Hindlimb motor maps in the intact state}

In intact rats, ICMS evoked movement of the contralateral hindlimb exclusively up to $100 \mu \mathrm{A}$. Hindlimb motor maps were centered between $0.5-3.0 \mathrm{~mm}$ posterior to bregma and $1.0-3.0$ $\mathrm{mm}$ lateral from midline (Figs. 5, 6A,F). Total hindlimb motor map size was $2.4 \pm 0.3 \mathrm{~mm}^{2}$ (Fig. $7 A$ and Fig. 2-1 available at https://doi.org/10.1523/JNEUROSCI.1062-18.2018.f2-1).

Hindlimb representations were bounded in the anterior aspect by the caudal end of central forelimb motor area, consistent with previous work in male Long-Evans rats (Neafsey et al., 1986). In some rats, hindlimb and forelimb representations were bounded by an intervening strip of trunk or tail representation. Evoked hindlimb responses comprised flexions of the hip (12.6 $\pm 9.0 \%$ of total hindlimb area), knee (19.7 $\pm 12.3 \%)$, ankle (50.0 \pm $11.0 \%)$, and toe $(17.7 \pm 9.5 \%$; Fig. $7 B)$. Mean stimulation intensity to evoke hindlimb movement was $54.1 \pm 9.3 \mu \mathrm{A}$ (Fig. $7 \mathrm{C}$ and Fig. 2-1 available at https://doi.org/10.1523/JNEUROSCI.106218.2018.f2-1). Hindlimb motor map size, location and movement thresholds observed presently in the female Long-Evans rat is similar to previous reports in Lewis (Fouad et al., 2001) and Fisher-444 (Frost et al., 2013) rats, indicating that hindlimb motor map organization is conserved across these strains.

\section{Dynamic reorganization of hindlimb motor maps after SCI}

One week following hemisection we observed a marked absence of hindlimb motor maps in both the ipsilesional (Fig. 6B) and contralesional (Fig. 6G) motor cortices. Hindlimb representations remained absent from contralesional motor cortex from 1 to 5 weeks after injury (Fig. $6 G-J$ ). While forelimb movements could be evoked from the caudal end of the central forelimb representation, there was no encroachment of either the neighboring forelimb representation or any other somatic movement representation within hindlimb cortical territory in the contralesional motor cortex. In the ipsilesional cortex, we observed a dynamic reorganization of hindlimb motor maps 2-4 weeks after hemisection (Fig. 6C-E). The ipsilesional cortex regained a representation of the contralesional hindlimb 2 weeks after hemisection that was significantly smaller $\left(0.9 \pm 0.3 \mathrm{~mm}^{2}\right)$ than in intact rats $\left(2.4 \pm 0.3 \mathrm{~mm}^{2}, F_{(4,35)}=35.9, p=6.19 \mathrm{E}-12\right.$, ANOVA, Tukey post hoc $p=0.001$; Figs. $6 C, 7 A$, and Fig. $2-1$ available at https://doi.org/10.1523/JNEUROSCI.1062-18.2018.f2-1). The ipsilesional cortex then gained transient, bilateral access to the spinal cord below the hemisection 3 weeks after injury demonstrated by ICMS evoking movement in both hindlimbs in $43.3 \pm$ $13.6 \%$ of hindlimb-responsive stimulation sites compared with 
Ipsilesional cortex

A

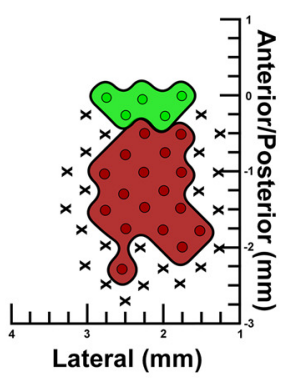

B

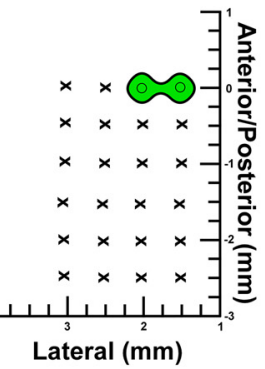

C

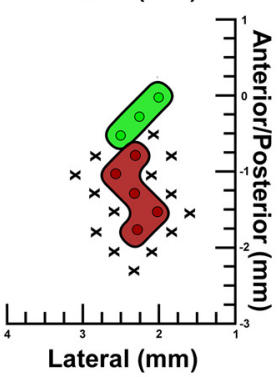

D

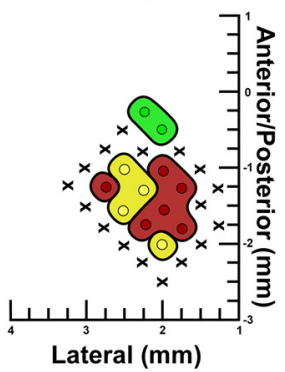

$\mathbf{E}$

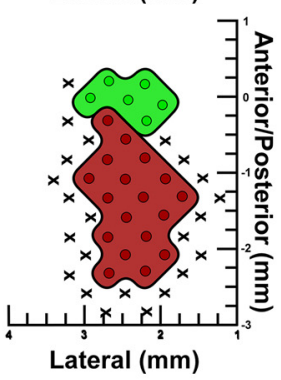

\section{Contralesional cortex}
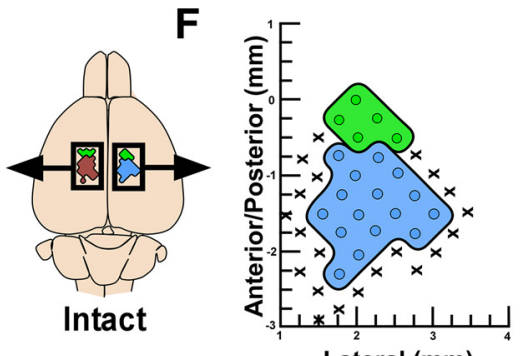

Lateral (mm)

G

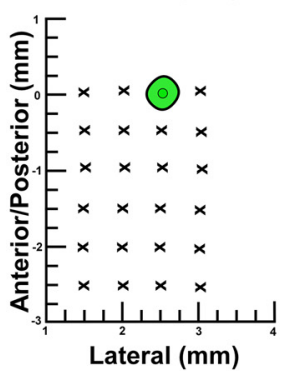

H

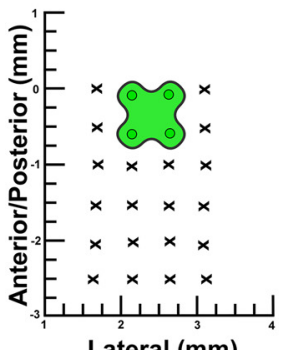

Lateral (mm)

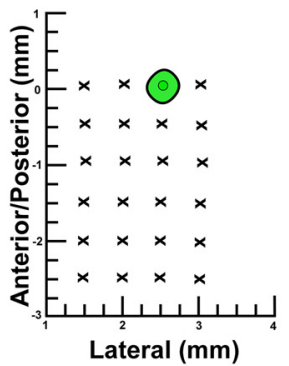

$\mathbf{J}$

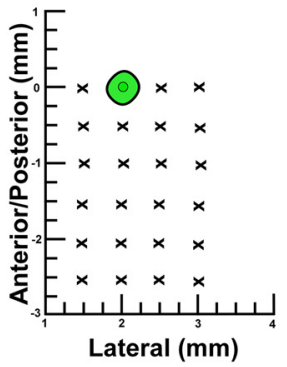

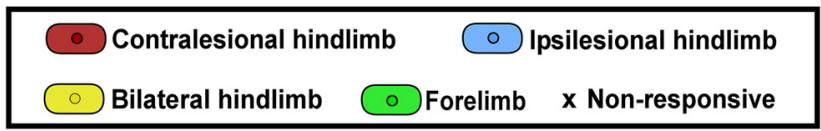

Figure 6. Dynamic reorganization of hindlimb motor maps after hemisection. $A, F$, In intact rats, hindlimb motor maps contain representations of contralateral joints (hip, knee, ankle, toe) exclusively. $\boldsymbol{B}, \boldsymbol{C}$, Ipsilesional hindlimb motor maps disappear in the initial week after hemisection and reappear 2 weeks after SCI. D, Three weeks after hemisection, the ipsilesional hindlimb motor maps reorganize to produce movements of both hindlimbs. $\boldsymbol{E}$, Four to 5 weeks after hemisection, the ipsilesional motor maps return to normal. $\mathbf{G}-\mathbf{J}$, Following hemisection, contralesional hindlimb motor maps remain absent for up to 5 weeks.

only contralateral movements in the intact state (Mann-Whitney $U=0.0, p=$ 0.0002 ; Figs. $6 A, D, 7 A$ ). Bilateral movements primarily involved hip or ankle flexion at the same movement threshold between hindlimbs. No significant difference in movement thresholds were observed between unilateral and bilateral hindlimb movements evoked 3 weeks after hemisection $\left(t_{(14)}=0.0238, p=\right.$ 0.981). Hindlimb motor map size in the ipsilesional cortex 3 weeks after hemisection was still significantly reduced $(1.2 \pm$ $0.3 \mathrm{~mm}^{2}$ ) compared with intact rats $\left(2.4 \pm 0.3 \mathrm{~mm}^{2}\right.$; Tukey post hoc $p=0.001$; Fig. 7A). Smaller hindlimb motor maps after hemisection were due to a significant reduction in the cortical area eliciting knee flexion 2 weeks after injury ( $p=$ 0.019 ) and ankle flexion 2-3 weeks after injury ( 2 weeks: $p=0.0012,3$ weeks: $p=$ 0.0004) compared with intact controls (Fig. 7B), indicating a graded proximal to distal recovery of joint representation over time. Four and 5 weeks after hemisection, the ipsilesional motor cortex regained a normal representation of the contralesional hindlimb (Figs. 6E, 7A). The results on map size were not due to significant changes in movement thresholds between groups, although a trend for increased thresholds was observed 2-3 weeks after hemisection $\left(F_{(4,35)}=2.38\right.$, $p=0.0701$, ANOVA; Fig. 7C). As the amount of ketamine-xylazine anesthesia administered during ICMS has been shown to influence both movement thresholds and map size (Tandon et al., 2008), this parameter was systematically controlled for in ICMS experiments. The mean amount of ketamine administered during electrophysiological mapping was $0.123 \pm 0.022 \mathrm{mg} / \mathrm{g} / \mathrm{h}$ and did not differ between groups $\left(F_{(5,42)}=0.868, p=\right.$ 0.511, ANOVA). Similarly, the mean amount of xylazine administered was $0.0317 \pm 0.0083 \mathrm{mg} / \mathrm{g} / \mathrm{h}$ and did not differ between groups $\left(F_{(5,42)}=0.959, p=\right.$ 0.454, ANOVA).

Inactivation of the ipsilesional motor cortex 3 weeks after SCI impairs hindlimb performance bilaterally on the horizontal ladder

We next sought to determine whether the dynamic reorganization of ipsilesional hindlimb motor maps after hemisection relate to behaviorally functional compensation of ipsilesional cortical control over the ipsilesional hindlimb after injury. We hypothesized that if the bilateral cortical hindlimb representations observed transiently 3 weeks after hemisection were 
A

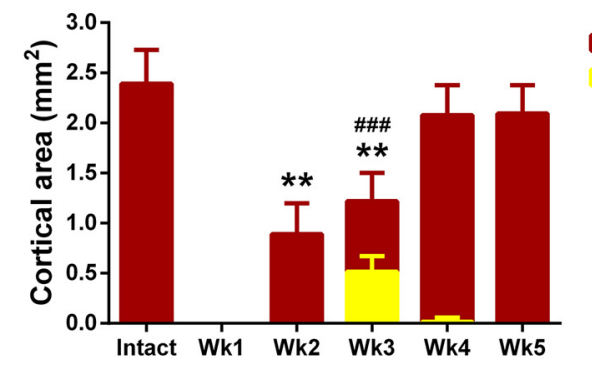

B

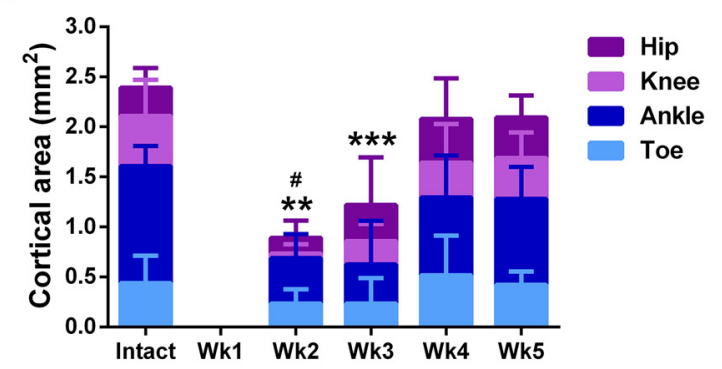

C

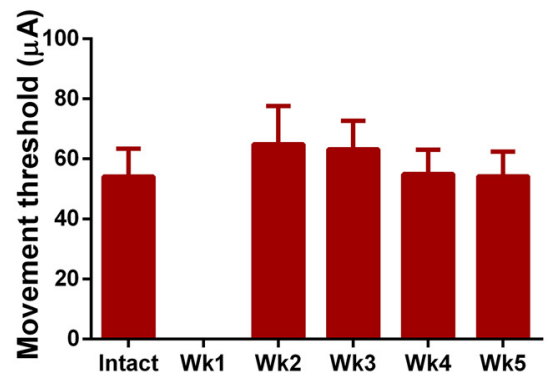

Figure 7. Quantification of ipsilesional motor map reorganization. $\boldsymbol{A}$, ICMS of the ipsilesional motor cortex evoked movement in both hindlimbs 3 weeks after hemisection, but not in the intact state. Statistical differences in the cortical area evoking bilateral hindlimb movement after hemisection from the intact state is showed by \#\#\# ( $p<0.001$, Mann-Whitney test). Statistical differences in the cortical area evoking contralateral hindlimb movement is showed by ${ }^{* *}(p<0.01$, ANOVA supplemented with Tukey HSD). $\boldsymbol{B}$, The smaller hindlimb motor maps in the ipsilesional motor cortex 2-3 weeks after hemisection were related to a significant decrease in ankle (showed by ${ }^{* *} p<0.01$ and ${ }^{* * *} p<0.001$, Tukey HSD) and knee (showed by $\# p<0.05$, Tukey HSD) representation. $\boldsymbol{C}$, Movement thresholds did not significantly differ between postlesion groups ( $p=0.0701$, ANOVA). All data are plotted as group mean \pm SD ( $n=8$ rats/group). See also Figure 2-1 (available at https://doi.org/10.1523/JNEUROSCI.106218.2018.f2-1) for individual values.

functionally relevant to locomotor recovery of the affected limb, then reversible inactivation of ipsilesional hindlimb motor cortex at this time point would impair locomotor performance bilaterally. To address this question, we used reversible cryogenic inactivation of the motor cortex in behaving rats (Brown and Teskey, 2014). In validation experiments, inactivation of hindlimb motor cortex was shown to reversibly abolish ICMS-evoked hindlimb movement the anesthetized rat (Fig. 8). Cryoloops targeting ipsilesional and contralesional hindlimb motor cortex were chronically implanted and rats were trained on the horizontal ladder-rung walking test. Ladder crossing performance was assessed in the intact state and for 5 weeks following hemisection before and during separate inactivation of the ipsilesional and contralesional cortices.

Before cortical inactivation, rats showed partial spontaneous hindlimb recovery in the ladder task (Fig. 9). There was a significant increase in foot-faults made by the ipsilesional hindlimb 1
A

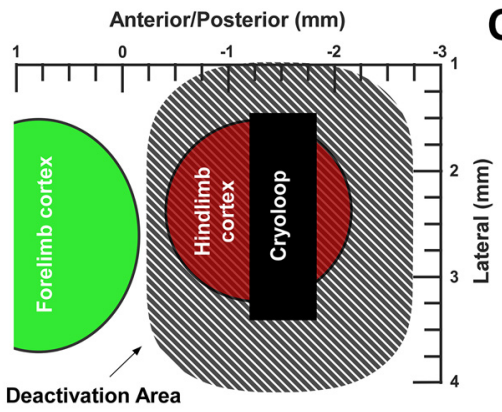

C

Deactivation Area

B

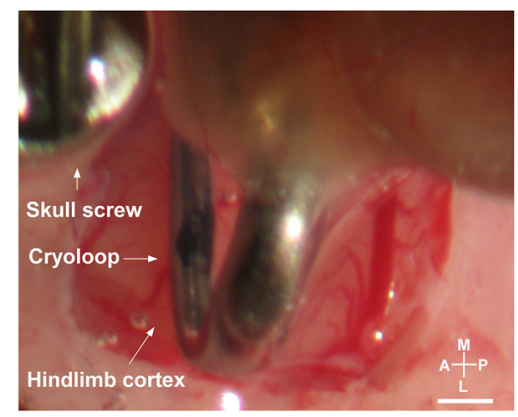

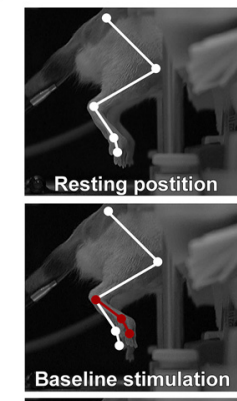

Baseline stimulation

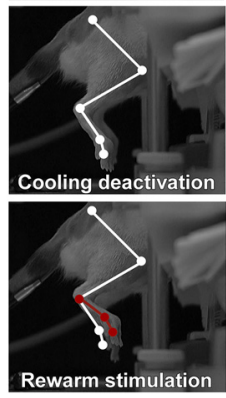

Figure 8. Inactivation of hindlimb motor cortex. $\boldsymbol{A}$, Schematic representation of the cortical inactivation area centered on the hindlimb motor map. $\boldsymbol{B}$, Photomicrograph of the cryoloop assembly placed over the hindlimb motor cortex. Scale bar, $500 \mu \mathrm{m}$. M, Medial; L, Lateral; A, anterior; P, posterior. C, Contralateral hindlimb movement evoked by ICMS is abolished during cooling inactivation and reinstated following passive rewarming of the cortex. White markers indicate the initial position on hindlimb joints (hip, knee, ankle, metatarsophalangeal, and toe) before stimulation. Red markers indicate maximal joint displacement during ankle flexion, if observed, from baseline during a $40 \mathrm{~ms}$ stimulation trial at $100 \mu \mathrm{A}$.

week after hemisection $(84.7 \pm 15.7 \%)$ compared with the intact state $\left(3.5 \pm 3.6 \% ; F_{(5,10)}=75.85, p=1.27 \mathrm{E}-7\right.$, ANOVA simple effect, Bonferroni post hoc $p=1.01 \mathrm{E}-14)$. Ladder crossing performance significantly improved for the ipsilesional hindlimb over the next 2 weeks after hemisection (Week 2: $58.9 \pm 4.7 \%$, $p=6.45 \mathrm{E}-6$; Week 3: $46.7 \pm 5.2 \%, p=0.035)$ until Week 4 $(35.7 \pm 7.4 \% ; p=0.075)$. A residual deficit in performance remained at 5 weeks $(25.1 \pm 9.2 \%)$ compared with the intact state $(p=8.00 \mathrm{E}-5)$. There was also a significant impairment in contralesional hindlimb performance during ladder walking 1 $(20.6 \pm 12.6 \%)$ and $2(11.5 \pm 6.7 \%)$ weeks after hemisection compared with intact values $\left(2.4 \pm 2.1 \%, F_{(5,10)}=9.56, p=\right.$ 0.00014 , ANOVA simple effect, Bonferroni post hoc $p=$ $5.5 \mathrm{E}-10, p=5.6 \mathrm{E}-5)$ that quickly recovered the following week $(7.8 \pm 3.9 \%, p=0.187)$. Inactivation of the ipsilesional hindlimb motor cortex 3 weeks after hemisection significantly increased the percentage of hindlimb foot-faults made by both the ipsilesional $\left(F_{(2,4)}=23.55, p=0.0061\right.$, ANOVA simple effect, Bonferroni post hoc $p=0.0001)$ and contralesional hindlimbs $\left(F_{(2,4)}=\right.$ 7.02, $p=0.049$, ANOVA simple effect, Bonferroni post hoc $p=$ 9.41E-9) during ladder walking (Fig. 9). In contrast, the same cortical inactivation applied to the contralesional cortex after hemisection or applied in the intact state had no impact on either hindlimb (all $p>0.05$ ). Importantly, the impact of ipsilesional cortical inactivation on disrupting hindlimb function was only effective on the third week after hemisection, demonstrating that the bilateral representations of hindlimb movements observed in the motor maps were functionally relevant to recovery. No significant changes in the percentage of footfaults made by the forelimbs were observed during inactivation of either cortex in the intact state or 3 weeks after hemisection (all $p>0.05$; Fig. 10). 


\section{A Ipsilesional hindlimb}

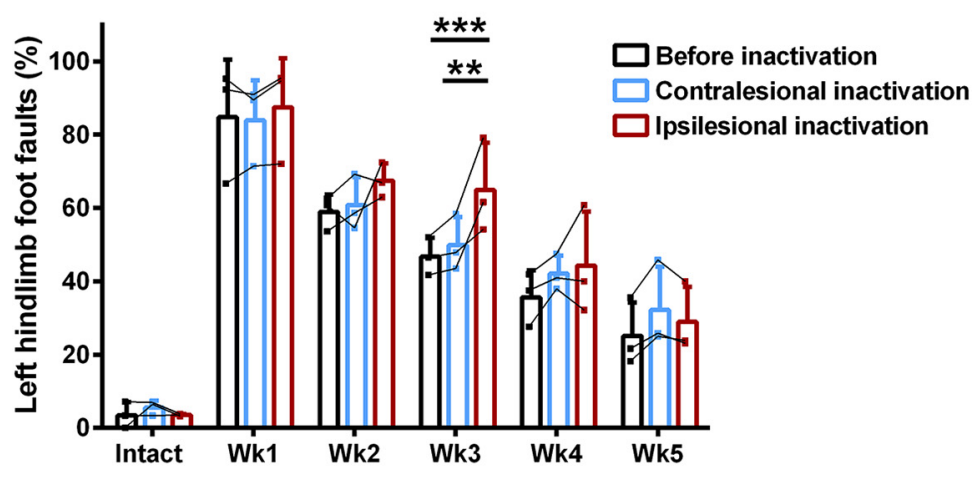

B Contralesional hindlimb

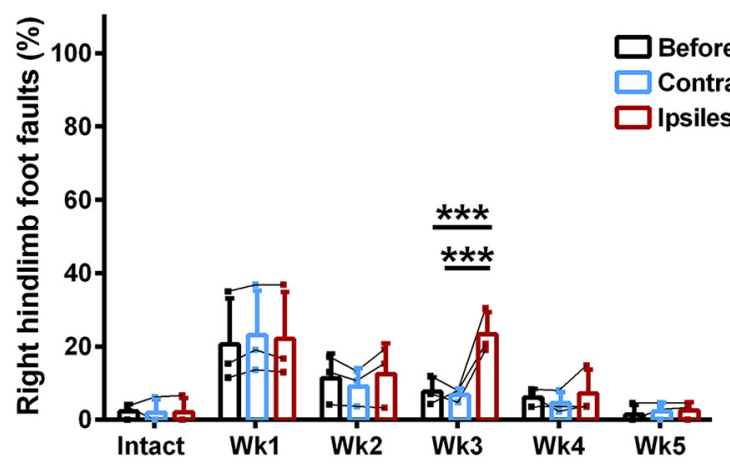

Figure 9. Effect of hindlimb motor cortex inactivation on hindlimb motor performance. Acute inactivation of the ipsilesional hindlimb motor cortex significantly increased foot faults of both $\boldsymbol{A}$, ipsilesional and $\boldsymbol{B}$, contralesional hindlimbs during ladder walking 3 weeks after hemisection compared with before inactivation and during contralesional cortical inactivation. Data are plotted as group mean \pm SD in three rats. Statistical evaluation was performed with a two-factor ANOVA supplemented with Bonferroni multiple-comparison tests, asterisks indicate significance: ${ }^{* *} p<0.01$, ${ }^{* * *} p<0.001$.

\section{Discussion}

We performed behavioral, electrophysiological, and cortical inactivation experiments to determine the time course of hindlimb motor cortex plasticity and its role in spontaneous partial hindlimb recovery after hemisection of the thoracic spinal cord in a rat model of unilateral SCI. We demonstrate that while hindlimb motor maps in the contralesional cortex are abolished for 5 weeks after hemisection, the ipsilesional cortex undergo dynamic plasticity to gain a transient representation of both hindlimbs 3 weeks after injury. This result indicates that after CST projections from the contralateral motor cortex were severed by the hemisection, the ipsilesional motor cortex gained access to the spinal cord below the lesion to produce movements of the ipsilesional hindlimb. We next evaluated whether cortical plasticity functionally relates to hindlimb motor recovery by reversibly inactivating the ipsilesional or contralesional hindlimb motor cortex during ladder walking. Inactivation of the ipsilesional hindlimb motor cortex 3 weeks after hemisection impaired performance of both hindlimbs. These findings indicate a role for ipsilesional motor cortex plasticity in supporting spontaneous hindlimb motor recovery after SCI.

Spontaneous hindlimb motor recovery after SCI

Locomotion was initially affected in both hindlimbs after hemisection. Importantly, the ipsilesional hindlimb was critically more affected than the contralesional hindlimb. Spontaneous recovery of joint articulation, active stepping, and weight support during locomotion in the open field occurred within 3 weeks, consistent with other studies using this SCI model in the rat (Ballermann and Fouad, 2006; Arvanian et al., 2009; Leszczynska et al., 2015). The coordination between forelimbs and hindlimbs on the side of the hemisection was also affected (Helgren and Goldberger, 1993; Bem et al., 1995; Barrière et al., 2010) and is likely due to interruption of various pathways connecting cervical and lumbar segments that couple the fore- and hindlimb locomotor circuits (Sherrington and Laslett, 1903; English, 1980; Courtine et al., 2008). During horizontal ladder walking, hindlimb foot-faults were significantly increased on both sides the first week after hemisection. The contralesional hindlimb recovered to intact values the following week. The ipsilesional hindlimb showed progressive improvement during the first 3 weeks after hemisection with residual deficits remaining until the end of experimental evaluation similar to a previous report (Ballermann and Fouad, 2006).

\section{Contralesional hindlimb motor maps are abolished after SCI}

Hindlimb responses could not be evoked by ICMS in the contralesional cortex for 5 weeks after hemisection, suggesting that it remained disconnected from its interneuronal and motoneural targets in the spinal cord below the lesion. Hindlimb motor maps are known to remain absent for up to 4 weeks after SCI disrupting both crossed CSTs (Fouad et al., 2001; Frost et al., 2015; Manohar et al., 2017). Selective lesions of both dorsal cervical CSTs in mice leads to a re-emergence of forelimb and hindlimb motor maps within both cortices during behavioral recovery, but recovery is prevented by subsequent silencing of spared dorsolateral CST projections (Hilton et al., 2016). As the injury model used in our study transects both dorsal and dorsolateral CST outputs from the contralateral cortex, the mouse result suggests that a combined lesion of both projections in the rat is required to prevent motor map re-emergence for up to 5 weeks after SCI. Expansion of adjacent forelimb or orofacial movement representation into hindlimb cortical territory was not observed, in contrast to selective bilateral dorsal funiculus lesions (Fouad et al., 2001). A lack of remapping in the hindlimb motor cortex is consistent with this area representing extensive sensorimotor overlap (Donoghue and Wise, 1982) that has been suggested to limit the extent of motor remapping after injury (Donoghue and Sanes, 1988; Giszter et al., 1998).

\section{Ipsilesional hindlimb motor maps reorganize after SCI}

Dynamic reorganization of hindlimb motor maps was observed in the ipsilesional cortex after hemisection. Hindlimb movements were not evoked in the ipsilesional cortex the first week after injury and hindlimb cortical area was smaller than normal the following week. A decline in transmission from uninjured contralesional CST fibers has been previously reported and 
linked to a temporary demyelination of intact axons during the first 2 weeks after hemisection (Arvanian et al., 2009). Decreased responsiveness of the ipsilesional hindlimb motor cortex to ICMS in the initial period after hemisection may also reflect a reduced ability to summate descending volleys at the spinal level (Cirillo et al., 2016) due to reduced interhemispheric (Aguilar et al., 2010) or spinal (Ditunno et al., 2004) excitability. Three weeks after hemisection, during the time of spontaneous hindlimb recovery, the ipsilesional motor cortex reorganized to develop a novel representation of both hindlimbs in a subset of stimulation sites. Forty-three $\pm 13 \%$ of hindlimb-responsive stimulation sites evoked movements of the two hindlimbs at this time point, whereas in the intact state, ICMS evokes contralateral hindlimb movements (Neafsey et al., 1986; Fouad et al., 2001). A role for cortical plasticity in the intact hemisphere after unilateral CST damage may also generalize to other injury models. After a controlled unilateral contusion to the motor cortex, reorganization of motor maps is observed in the uninjured motor cortex where ICMS begins to evoke bilateral movement of the limbs (Axelson et al., 2013). Following unilateral cortical stroke (Witte et al., 2000; Shimizu et al., 2002; Rehme et al., 2012) and SCI (Frost et al., 2015) there is increased motor cortex activity contralateral to the lesion that may be capable of significant compensation for contralateral cortical dysfunction in humans (Strens et al., 2003). Midline-crossing CST fibers arborize in the intermediate laminae of contralateral spinal gray matter after SCI (Fouad et al., 2001; Raineteau et al., 2002; Ghosh et al., 2009, 2010). Collateral sprouting of undamaged ipsilesional CST fibers could innervate contralateral interneuronal and motoneuronal pools and allow movements of both hindlimbs from stimulation of the ipsilesional cortex. Although the uncrossed ventral CST projection from the ipsilesional cortex (Brösamle and Schwab, 1997) can also promote functional recovery after unilateral injury, it was not consistently spared between rats. From the fourth week after hemisection, bilateral hindlimb movements were no longer evoked by ICMS. At this time point cortical synaptic remodeling and pruning occurs (Kim et al., 2006). The loss of bilateral hindlimb representations after hemisection may reflect a refinement of synaptic connections in subcortical motor circuits including the cerebellum (Proville et al., 2014), basal ganglia (Turner and Desmurget, 2010), reticular formation (Zörner et al., 2014), or spinal cord (Alluin et al., 2009; Martinez et al., 2011, 2012a,b, 2013; Gossard et al., 2015) that may be shaped to support hindlimb control after injury.

\section{Cortical plasticity participates in hindlimb motor recovery after SCI}

Inactivation of the ipsilesional hindlimb motor cortex 3 weeks after hemisection, at the time in which it expressed a bilateral representation of the hindlimbs, impaired ladder walking perfor-
Ipsilesional forelimb

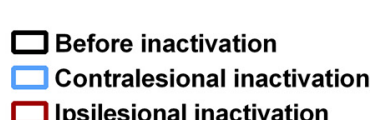

$\square$ Ipsilesional inactivation

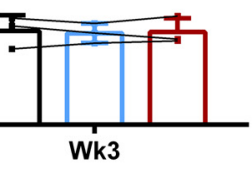

Contralesional forelimb

Figure 10. Effect of hindlimb motor cortex inactivation on forelimb motor performance. Acute inactivation of the either the ipsilesional and contralesional hindlimb motor cortex in the intact state or 3 weeks after hemisection did not affect the foot-faults made by the $\boldsymbol{A}$, ipsilesional or $\boldsymbol{B}$, contralesional forelimbs during ladder walking (all $p>0.05$, two-factor ANOVA supplemented with Bonferroni multiple-comparison tests). Data are plotted as group mean \pm SD in three rats.

mance of both hindlimbs. Performance was impaired to levels observed 1 week after hemisection, suggesting that plasticity of the ipsilesional motor cortex is participating in hindlimb motor recovery after injury. Inactivation of hindlimb motor cortex did not affect hindlimb performance on the ladder in the intact state or at other time points after hemisection. This would also suggest that in the intact state hindlimb motor performance in the rat is less sensitive to cortical inhibition than the forelimbs (Brown and Teskey, 2014) and ipsilesional cortical plasticity after hemisection strengthened corticospinal input to spinal circuits below the lesion bilaterally that were sensitive to cortical inhibition. Similar results have also been reported where focal lesions of the hindlimb and trunk motor cortex in rats produce no treadmill locomotor deficits in the intact state, but do after spinal transection indicating that locomotor recovery becomes cortically dependent in some SCI models (Giszter et al., 2008).

The contralesional cortex may resume voluntary control over the ipsilesional hindlimb at later stages after injury. Movements evoked by ICMS predominantly reflect CST connectivity of the motor cortex to the interneuronal and motoneuronal pools in the spinal cord as they are abolished by pyramidotomy (Brus-Ramer et al., 2009) and ICMS of the motor cortex 3 months after dorsal spinal hemisection evokes hindlimb movements that are also abolished by subsequent pyramidotomy (Bareyre et al., 2004). An absence of motor maps, however, does not preclude activity in the motor cortex from influencing descending motor control via indirect spinal cord projections which can be influenced by cortical synaptic block provided by cooling inactivation, particularly 
after CST injury. After unilateral CST damage in the macaque, precision grasping of the affected forelimb increases regional cerebral blood flow in both motor cortices in the early ( $\leq 1$ month) recovery stage, and then solely in the contralesional motor cortex in the late ( $\geq 3$ months) recovery state (Nishimura et al., 2007). A similar process may occur in the rat where the contralesional hindlimb motor cortex gains enhanced indirect access to the spinal cord that is not activated by ICMS. In parallel, cortical (Giszter et al., 2008), subcortical (Ballermann and Fouad, 2006; Filli et al., 2014; Zörner et al., 2014), and spinal (Alluin et al., 2009; Martinez et al., 2011, 2012a; Gossard et al., 2015) networks can spontaneously reorganize to assume control of the affected hindlimb after CST damage.

\section{References}

Aguilar J, Humanes-Valera D, Alonso-Calviño E, Yague JG, Moxon KA, Oliviero A, Foffani G (2010) Spinal cord injury immediately changes the state of the brain. J Neurosci 30:7528 -7537. CrossRef Medline

Alluin O, Leblond M, Tran S, Rossignol S (2009) Recovery of stepping after spinal transection in the rat. Soc Neurosci Abstr 35:766.8.

Arvanian VL, Schnell L, Lou L, Golshani R, Hunanyan A, Ghosh A, Pearse DD, Robinson JK, Schwab ME, Fawcett JW, Mendell LM (2009) Chronic spinal hemisection in rats induces a progressive decline in transmission in uninjured fibers to motoneurons. Exp Neurol 216:471-480. CrossRef Medline

Axelson HW, Winkler T, Flygt J, Djupsjö A, Hånell A, Marklund N (2013) Plasticity of the contralateral motor cortex following focal traumatic brain injury in the rat. Restor Neurol Neurosci 31:73-85. CrossRef Medline

Ballermann M, Fouad K (2006) Spontaneous locomotor recovery in spinal cord injured rats is accompanied by anatomical plasticity of reticulospinal fibers. Eur J Neurosci 23:1988-1996. CrossRef Medline

Bareyre FM, Kerschensteiner M, Raineteau O, Mettenleiter TC, Weinmann O, Schwab ME (2004) The injured spinal cord spontaneously forms a new intraspinal circuit in adult rats. Nat Neurosci 7:269-277. CrossRef Medline

Barrière G, Frigon A, Leblond H, Provencher J, Rossignol S (2010) Dual spinal lesion paradigm in the cat: evolution of the kinematic locomotor pattern. J Neurophysiol 104:1119-1133. CrossRef Medline

Bem T, Górska T, Majczyński H, Zmysłowski W (1995) Different patterns of fore-hindlimb coordination during overground locomotion in cats with ventral and lateral spinal lesions. Exp Brain Res 104:70-80. CrossRef Medline

Biernaskie J, Corbett D (2001) Enriched rehabilitative training promotes improved forelimb motor function and enhanced dendritic growth after focal ischemic injury. J Neurosci 21:5272-5280. CrossRef Medline

Brösamle C, Schwab ME (1997) Cells of origin, course, and termination patterns of the ventral, uncrossed component of the mature rat corticospinal tract. J Comp Neurol 386:293-303. CrossRef Medline

Brown AR, Martinez M (2016) Time-dependent bilateral cortical plasticity parallels locomotor recovery after unilateral spinal cord injury in rats. Soc Neurosci Abstr 42:59.01.

Brown AR, Teskey GC (2014) Motor cortex is functionally organized as a set of spatially distinct representations for complex movements. J Neurosci 34:13574-13585. CrossRef Medline

Brown AR, Hu B, Antle MC, Teskey GC (2009) Neocortical movement representations are reduced and reorganized following bilateral intrastriatal 6-hydroxydopamine infusion and dopamine type-2 receptor antagonism. Exp Neurol 220:162-170. CrossRef Medline

Brus-Ramer M, Carmel JB, Martin JH (2009) Motor cortex bilateral motor representation depends on subcortical and interhemispheric interactions. J Neurosci 29:6196-6206. CrossRef Medline

Cirillo J, Calabro FJ, Perez MA (2016) Impaired organization of pairedpulse tms-induced i-waves after human spinal cord injury. Cereb Cortex 26:2167-2177. CrossRef Medline

Classen J, Liepert J, Wise SP, Hallett M, Cohen LG (1998) Rapid plasticity of human cortical movement representation induced by practice. J Neurophysiol 79:1117-1123. CrossRef Medline

Cohen LG, Bandinelli S, Findley TW, Hallett M (1991) Motor reorganization after upper limb amputation in man: a study with focal magnetic stimulation. Brain 114:615-627. CrossRef Medline
Combs HL, Jones TA, Kozlowski DA, Adkins DL (2016) Combinatorial motor training results in functional reorganization of remaining motor cortex after controlled cortical impact in rats. J Neurotrauma 33:741-747. CrossRef Medline

Courtine G, Song B, Roy RR, Zhong H, Herrmann JE, Ao Y, Qi J, Edgerton VR, Sofroniew MV (2008) Recovery of supraspinal control of stepping via indirect propriospinal relay connections after spinal cord injury. Nat Med 14:69-74. CrossRef Medline

Ditunno JF, Little JW, Tessler A, Burns AS (2004) Spinal shock revisited: a four-phase model. Spinal Cord 42:383-395. CrossRef Medline

Donoghue JP, Sanes JN (1988) Organization of adult motor cortex representation patterns following neonatal forelimb nerve injury in rats. J Neurosci 8:3221-3232. CrossRef Medline

Donoghue JP, Wise SP (1982) The motor cortex of the rat: cytoarchitecture and microstimulation mapping. J Comp Neurol 212:76-88. CrossRef Medline

English AW (1980) Interlimb coordination during stepping in the cat: effects of dorsal column section. J Neurophysiol 44:270-279. CrossRef Medline

Filli L, Engmann AK, Zörner B, Weinmann O, Moraitis T, Gullo M, Kasper H, Schneider R, Schwab ME (2014) Bridging the gap: a reticulopropriospinal detour bypassing an incomplete spinal cord injury. J Neurosci 34:13399-13410. CrossRef Medline

Fouad K, Pedersen V, Schwab ME, Brösamle C (2001) Cervical sprouting of corticospinal fibers after thoracic spinal cord injury accompanies shifts in evoked motor responses. Curr Biol 11:1766-1770. CrossRef Medline

Frost SB, Iliakova M, Dunham C, Barbay S, Arnold P, Nudo RJ (2013) Reliability in the location of hindlimb motor representations in fischer-344 rats. J Neurosurg Spine 19:248-255. CrossRef Medline

Frost SB, Dunham CL, Barbay S, Krizsan-Agbas D, Winter MK, Guggenmos DJ, Nudo RJ (2015) Output properties of the cortical hindlimb motor area in spinal cord-injured rats. J Neurotrauma 32:1666-1673. CrossRef Medline

Ghosh A, Sydekum E, Haiss F, Peduzzi S, Zörner B, Schneider R, Baltes C, Rudin M, Weber B, Schwab ME (2009) Functional and anatomical reorganization of the sensory-motor cortex after incomplete spinal cord injury in adult rats. J Neurosci 29:12210-12219. CrossRef Medline

Ghosh A, Haiss F, Sydekum E, Schneider R, Gullo M, Wyss MT, Mueggler T, Baltes C, Rudin M, Weber B, Schwab ME (2010) Rewiring of hindlimb corticospinal neurons after spinal cord injury. Nat Neurosci 13:97-104. CrossRef Medline

Girgis J, Merrett D, Kirkland S, Metz GA, Verge V, Fouad K (2007) Reaching training in rats with spinal cord injury promotes plasticity and task specific recovery. Brain 130:2993-3003. CrossRef Medline

Giszter SF, Kargo WJ, Davies M, Shibayama M (1998) Fetal transplants rescue axial muscle representations in $\mathrm{m} 1$ cortex of neonatally transected rats that develop weight support. J Neurophysiol 80:3021-3030. CrossRef Medline

Giszter S, Davies MR, Ramakrishnan A, Udoekwere UI, Kargo WJ (2008) Trunk sensorimotor cortex is essential for autonomous weight-supported locomotion in adult rats spinalized as $\mathrm{p} 1 / \mathrm{p} 2$ neonates. J Neurophysiol 100:839-851. CrossRef Medline

Gossard JP, Delivet-Mongrain H, Martinez M, Kundu A, Escalona M, Rossignol S (2015) Plastic changes in lumbar locomotor networks after a partial spinal cord injury in cats. J Neurosci 35:9446-9455. CrossRef Medline

Helgren ME, Goldberger ME (1993) The recovery of postural reflexes and locomotion following low thoracic hemisection in adult cats involves compensation by undamaged primary afferent pathways. Exp Neurol 123:17-34. CrossRef Medline

Hilton BJ, Anenberg E, Harrison TC, Boyd JD, Murphy TH, Tetzlaff W (2016) Re-establishment of cortical motor output maps and spontaneous functional recovery via spared dorsolaterally projecting corticospinal neurons after dorsal column spinal cord injury in adult mice. J Neurosci 36:4080-4092. CrossRef Medline

Karni A, Meyer G, Rey-Hipolito C, Jezzard P, Adams MM, Turner R, Ungerleider LG (1998) The acquisition of skilled motor performance: fast and slow experience-driven changes in primary motor cortex. Proc Natl Acad Sci U S A 95:861-868. CrossRef Medline

Kim BG, Dai HN, McAtee M, Vicini S, Bregman BS (2006) Remodeling of synaptic structures in the motor cortex following spinal cord injury. Exp Neurol 198:401-415. CrossRef Medline 
Kleim JA, Hogg TM, VandenBerg PM, Cooper NR, Bruneau R, Remple M (2004) Cortical synaptogenesis and motor map reorganization occur during late, but not early, phase of motor skill learning. J Neurosci 24 : 628-633. CrossRef Medline

Leszczyńska AN, Majczyński H, Wilczyński GM, Sławińska U, Cabaj AM (2015) Thoracic hemisection in rats results in initial recovery followed by a late decrement in locomotor movements, with changes in coordination correlated with serotonergic innervation of the ventral horn. PLoS One 10:e 0143602. CrossRef Medline

Lomber SG, Payne BR (1996) Removal of two halves restores the whole: reversal of visual hemineglect during bilateral cortical or collicular inactivation in the cat. Vis Neurosci 13:1143-1156. CrossRef Medline

Lomber SG, Payne BR, Horel JA (1999) The cryoloop: an adaptable reversible cooling deactivation method for behavioral or electrophysiological assessment of neural function. J Neurosci Methods 86:179-194. CrossRef Medline

Manohar A, Foffani G, Ganzer PD, Bethea JR, Moxon KA (2017) Cortexdependent recovery of unassisted hindlimb locomotion after complete spinal cord injury in adult rats. eLife 6:e23532. CrossRef Medline

Martinez M, Brezun JM, Bonnier L, Xerri C (2009) A new rating scale for open-field evaluation of behavioral recovery after cervical spinal cord injury in rats. J Neurotrauma 26:1043-1053. CrossRef Medline

Martinez M, Delcour M, Russier M, Zennou-Azogui Y, Xerri C, Coq JO, Brezun JM (2010) Differential tactile and motor recovery and cortical map alteration after c4-c5 spinal hemisection. Exp Neurol 221:186-197. CrossRef Medline

Martinez M, Delivet-Mongrain H, Leblond H, Rossignol S (2011) Recovery of hindlimb locomotion after incomplete spinal cord injury in the cat involves spontaneous compensatory changes within the spinal locomotor circuitry. J Neurophysiol 106:1969-1984. CrossRef Medline

Martinez M, Delivet-Mongrain H, Leblond H, Rossignol S (2012a) Incomplete spinal cord injury promotes durable functional changes within the spinal locomotor circuitry. J Neurophysiol 108:124-134. CrossRef Medline

Martinez M, Delivet-Mongrain H, Leblond H, Rossignol S (2012b) Effect of locomotor training in completely spinalized cats previously submitted to a spinal hemisection. J Neurosci 32:10961-10970. CrossRef Medline

Martinez M, Delivet-Mongrain H, Rossignol S (2013) Treadmill training promotes spinal changes leading to locomotor recovery after partial spinal cord injury in cats. J Neurophysiol 109:2909-2922. CrossRef Medline

Metz GA, Whishaw IQ (2002) Cortical and subcortical lesions impair skilled walking in the ladder rung walking test: a new task to evaluate foreand hindlimb stepping, placing, and co-ordination. J Neurosci Methods 115:169-179. CrossRef Medline

Neafsey EJ, Bold EL, Haas G, Hurley-Gius KM, Quirk G, Sievert CF, Terreberry RR (1986) The organization of the rat motor cortex: a microstimulation mapping study. Brain Res 396:77-96. CrossRef Medline

Nishibe M, Barbay S, Guggenmos D, Nudo RJ (2010) Reorganization of motor cortex after controlled cortical impact in rats and implications for functional recovery. J Neurotrauma 27:2221-2232. CrossRef Medline

Nishimura Y, Onoe H, Morichika Y, Perfiliev S, Tsukada H, Isa T (2007) Time-dependent central compensatory mechanisms of finger dexterity after spinal cord injury. Science 318:1150-1155. CrossRef Medline

Nudo RJ, Milliken GW (1996) Reorganization of movement representations in primary motor cortex following focal ischemic infarcts in adult squirrel monkeys. J Neurophysiol 75:2144-2149. CrossRef Medline

Nudo RJ, Jenkins WM, Merzenich MM (1990) Repetitive microstimulation alters the cortical representation of movements in adult rats. Somatosens Mot Res 7:463-483. CrossRef Medline

Nudo RJ, Milliken GW, Jenkins WM, Merzenich MM (1996) Usedependent alterations of movement representations in primary motor cortex of adult squirrel monkeys. J Neurosci 16:785-807. CrossRef Medline
Oza CS, Giszter SF (2014) Plasticity and alterations of trunk motor cortex following spinal cord injury and non-stepping robot and treadmill training. Exp Neurol 256:57-69. CrossRef Medline

Proville RD, Spolidoro M, Guyon N, Dugué GP, Selimi F, Isope P, Popa D, Léna C (2014) Cerebellum involvement in cortical sensorimotor circuits for the control of voluntary movements. Nat Neurosci 17:12331239. CrossRef Medline

Raineteau O, Fouad K, Bareyre FM, Schwab ME (2002) Reorganization of descending motor tracts in the rat spinal cord. Eur J Neurosci 16:17611771. CrossRef Medline

Rehme AK, Eickhoff SB, Rottschy C, Fink GR, Grefkes C (2012) Activation likelihood estimation meta-analysis of motor-related neural activity after stroke. Neuroimage 59:2771-2782. CrossRef Medline

Sherrington CS, Laslett EE (1903) Observations on some spinal reflexes and the interconnection of spinal segments. J Physiol 29:58-96. CrossRef Medline

Shimizu T, Hosaki A, Hino T, Sato M, Komori T, Hirai S, Rossini PM (2002) Motor cortical disinhibition in the unaffected hemisphere after unilateral cortical stroke. Brain 125:1896-1907. CrossRef Medline

Soblosky JS, Colgin LL, Chorney-Lane D, Davidson JF, Carey ME (1997) Ladder beam and camera video recording system for evaluating forelimb and hindlimb deficits after sensorimotor cortex injury in rats. J Neurosci Methods 78:75-83. CrossRef Medline

Strens LH, Fogelson N, Shanahan P, Rothwell JC, Brown P (2003) The ipsilateral human motor cortex can functionally compensate for acute contralateral motor cortex dysfunction. Curr Biol 13:1201-1205. CrossRef Medline

Tandon S, Kambi N, Jain N (2008) Overlapping representations of the neck and whiskers in the rat motor cortex revealed by mapping at different anaesthetic depths. Eur J Neurosci 27:228-237. CrossRef Medline

Teskey GC, Monfils MH, VandenBerg PM, Kleim JA (2002) Motor map expansion following repeated cortical and limbic seizures is related to synaptic potentiation. Cereb Cortex 12:98-105. CrossRef Medline

Touvykine B, Mansoori BK, Jean-Charles L, Deffeyes J, Quessy S, Dancause N (2016) The effect of lesion size on the organization of the ipsilesional and contralesional motor cortex. Neurorehabil Neural Repair 30:280-292. CrossRef Medline

Traversa R, Cicinelli P, Bassi A, Rossini PM, Bernardi G (1997) Mapping of motor cortical reorganization after stroke: a brain stimulation study with focal magnetic pulses. Stroke 28:110-117. CrossRef Medline

Turner RS, Desmurget M (2010) Basal ganglia contributions to motor control: a vigorous tutor. Curr Opin Neurobiol 20:704-716. CrossRef Medline

Vichaya EG, Baumbauer KM, Carcoba LM, Grau JW, Meagher MW (2009) Spinal glia modulate both adaptive and pathological processes. Brain Behav Immun 23:969-976. CrossRef Medline

Witte OW, Bidmon HJ, Schiene K, Redecker C, Hagemann G (2000) Functional differentiation of multiple perilesional zones after focal cerebral ischemia. J Cereb Blood Flow Metab 20:1149-1165. CrossRef Medline

Wittenberg GF (2010) Experience, cortical remapping, and recovery in brain disease. Neurobiol Dis 37:252-258. CrossRef Medline

Yang XF, Kennedy BR, Lomber SG, Schmidt RE, Rothman SM (2006) Cooling produces minimal neuropathology in neocortex and hippocampus. Neurobiol Dis 23:637-643. CrossRef Medline

Young NA, Vuong J, Flynn C, Teskey GC (2011) Optimal parameters for microstimulation derived forelimb movement thresholds and motor maps in rats and mice. J Neurosci Methods 196:60-69. CrossRef Medline

Zörner B, Bachmann LC, Filli L, Kapitza S, Gullo M, Bolliger M, Starkey ML, Röthlisberger M, Gonzenbach RR, Schwab ME (2014) Chasing central nervous system plasticity: the brainstem's contribution to locomotor recovery in rats with spinal cord injury. Brain 137:1716-1732. CrossRef Medline 